\title{
CORRESPONDENCE
}

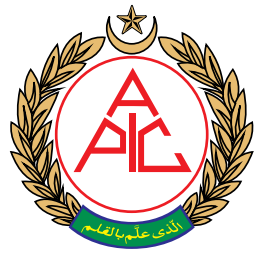

\section{Propofol infusion syndrome}

Citation: Hasan SS. Propofol infusion syndrome. Anaesth. pain intensive care $2020 ; 24(2): 253$

DOI: $\underline{\text { https://doi.org/10.35975/apic.v24i2.1265 }}$

I am writing in order to stress upon the correct and safe rate of propofol infusion in intensive care unit (ICU) as a high rate of infusion can easily be missed and can lead to serious consequences. Propofol infusion syndrome (PRIS) is a well-known entity, which has been reported in both children and adults and is related to its high rates. First death due to PRIS was reported in 1990. The term was originally coined in 1998 by Bray to describe the adverse effects with its use in pediatric population. Though the first case was reported in a child, it has now been increasingly reported in adult ICU patients too.

PRIS can result in acute refractory bradycardia to asystole in the presence of metabolic acidosis, rhabdomyolysis, renal failure and hypertriglyceridemia. In ICU, sedation is used for a long period of time in order for the patients to tolerate and comply with the mechanical ventilation. The most commonly used sedation in most of the units is propofol, which has been considered as a safe and an effective drug for this purpose if used in correct doses. I feel the risk of it's usage in excessive amount has gone higher with the recent change in its concentration from $1 \%$ to $2 \%$. We also use $2 \%$ propofol infusion in our unit. The safe limit for propofol infusion in ICU is to keep it under 4 $\mathrm{mg} / \mathrm{kg} / \mathrm{h}$.

In order to monitor the practice in our unit, we conducted an audit on its rate of infusion being used. The spot check of 1-2 patients per week over a 3 months period was carried out. The data of 31 patient-days was collected over this period. Estimated vs. actual rate based on patients weight were noted. We observed that $26(86 \%)$ of the patients received a correct rate of infusion on the basis of per kg body weight, and $2(6.6 \%)$ patients had propofol exceeding the safe limits. We found out that our practice was largely within the safe limits.

We conclude with the recommendations that the patients need to be more rigorously weighed on admission to ICU or when stable to do so and to consider documenting rates $/ \mathrm{kg} / \mathrm{h}$ in order to avoid infusion rates exceeding the safe limits. Particular care is needed in patients with low BMI and in patients with estimated weight.

\section{S. Shakir Hasan,}

Consultant Anaesthetist,

West Cumberland Hospital

Cumbria, UK

Correspondence: S. Shakir Hasan, 23 Parkgate Road,

Altrincham WA14 5UU, UK 